Check for updates

Cite this: RSC Adv., 2019, 9, 27117

Received 13th May 2019

Accepted 19th August 2019

DOI: 10.1039/c9ra03574e

rsc.li/rsc-advances

\title{
Approaching subthreshold-swing limit for thin-film transistors by using a giant-dielectric-constant gate dielectric $\uparrow$
}

\author{
Zhuo Chen, Linfeng Lan (D) * and Junbiao Peng
}

\begin{abstract}
Low-temperature giant-dielectric-constant thin films $\left(\mathrm{In}_{0.0025} \mathrm{Nb}_{0.0025} \mathrm{Ti}_{0.995} \mathrm{O}_{2}\right)$ fabricated with simple radio frequency $(\mathrm{RF})$ sputtering on glass substrates are employed as the gate dielectrics for thin-film transistors (TFTs) for the first time. The $380 \mathrm{~nm}$-thick $\mathrm{In}_{0.0025} \mathrm{Nb}_{0.0025} \mathrm{Ti}_{0.995} \mathrm{O}_{2}$ film exhibited a quasistatic capacitance of as high as $36156 \mathrm{nF} \mathrm{cm}{ }^{-2}$ with a quasi-static permittivity of 15525 (and $7607 \mathrm{nF}$ $\mathrm{cm}^{-2}$ at $1 \mathrm{kHz}$ ). Indium zinc oxide (IZO) TFTs with $\mathrm{In}_{0.0025} \mathrm{Nb}_{0.0025} \mathrm{Ti}_{0.995} \mathrm{O}_{2}$ gate dielectrics exhibited high output current at low operation voltage and little hysteresis in the transfer curves between forward and reverse sweeps. The subthreshold swing (SS) of the IZO TFTs is $0.068 \mathrm{~V} \mathrm{dec}^{-1}$, very close to the lowest limit of the SS of the field-effect transistors $\left(0.06 \mathrm{~V} \mathrm{dec}^{-1}\right)$. The results also proves that the lowest limit of the SS $\left(0.06 \mathrm{~V} \mathrm{dec}{ }^{-1}\right.$ ) cannot be broken no matter how high the gate dielectric capacitance is (except for negative capacitors). The TFTs demonstrate the potential for the applications in low-power circuits or flat-panel displays.
\end{abstract}

\section{Introduction}

The gate dielectric is important for a thin-film transistor (TFT), because the performance of the TFT device is affected by the interface/bulk traps, interface coupling, dielectric constant, leakage current, and breakdown field of the gate dielectric. For applications in active-matrix (AM) displays, especially for the AM organic light-emitting diode (OLED) displays, TFTs should be of high output current at relatively low operation voltage to meet the driving current of the OLEDs and reduce the power consumption. In AMOLEDs, the total power consumption $\left(P_{\text {total }}\right)$ of each pixel mainly depends on the OLED power consumption $\left(P_{\text {OLED }}\right)$ and the TFT power consumption $\left(P_{\text {TFT }}\right)$ :

$$
P_{\text {total }} \approx \eta_{\text {video }} \times\left(P_{\mathrm{OLED}}+P_{\mathrm{TFT}}\right) \propto\left(V_{\mathrm{OLED}}+V_{\mathrm{TFT}}\right)
$$

where $\eta_{\text {video }}$ is the percentage of on state of the pixels during the video operation, $V_{\text {OLED }}$ is the voltage drop of the OLED, and $V_{\text {TFT }}$ is the voltage drop of the TFT. It has been reported that $P_{\mathrm{TFT}}$ can be greater than $50 \%$ of $P_{\text {total }}$ when the mobility is lower than 5 $\mathrm{cm}^{2} \mathrm{~V}^{-1} \mathrm{~s}^{-1}{ }^{1}$ Therefore, reducing the operation voltage of TFTs is an effective way for reducing the power consumption for AMOLEDs.

State Key Laboratory of Luminescent Materials and Devices, South China University of Technology, Guangzhou 510640, China. E-mail: lanlinfeng@scut.edu.cn

$\dagger$ Electronic supplementary information (ESI) available: (1) Histograms of the (a) mobility and (b) threshold voltage of the IZO-TFT with the $\mathrm{In}_{0.0025} \mathrm{Nb}_{0.0025} \mathrm{Ti}_{0.995} \mathrm{O}_{2}$ gate dielectric. (2) The enlarge transfer curves of Fig. 10b. (3) The variations of time-dependent transfer curves of the IZO-TFT with the $\operatorname{In}_{0.0025} \mathrm{Nb}_{0.0025} \mathrm{Ti}_{0.995} \mathrm{O}_{2}$ insulator under negative gate bias stress. See DOI: 10.1039/c9ra03574e.
As known, the operation voltage of TFTs is determined by subthreshold swing (SS), which is defined as the change in gate voltage $\left(V_{\mathrm{G}}\right)$ required for one order change in the drain current $\left(I_{\mathrm{D}}\right)$. TFTs with lower SS usually have lower operation voltage. To lower the operation voltage and SS, fabricating TFTs with highcapacitance gate dielectric is the topic intriguing researchers in the industry and academia. Generally, there are two ways to increase the capacitance of the gate dielectrics-reducing the thickness or increasing the dielectric constant $(k)$ of the gate dielectrics. For practical application to active-matrix displays, the thickness of the gate dielectrics of TFTs should be greater than $200 \mathrm{~nm}$ to avoid electrical breakdown in the whole panel. In this case, further reducing the dielectric thickness to less than $200 \mathrm{~nm}$ would risk increasing of defects in the displays. Therefore, employing high dielectric constant dielectrics to increase the capacitance is preferred. Various high- $k$ dielectric materials have been applied to TFTs, such as $\mathrm{HfO}_{2}, \mathrm{Al}_{2} \mathrm{O}_{3}$ and etc. ${ }^{2,3}$ However, the dielectric constants of most of the high- $k$ materials are less than 40 . So these materials have a limited effect of reducing the operating voltage of the transistors.

At the same time, some research teams employed ferroelectrics as the gate dielectrics, ${ }^{4,5}$ such as $\mathrm{BaTiO}_{3}\left(\mathrm{BTO}, k_{\text {bulk }} \sim 10^{3}\right.$; $\left.k_{\text {film }} \sim 500\right), \mathrm{Pb}(\mathrm{Zr}, \mathrm{Ti}) \mathrm{O}_{3}\left(\mathrm{PZT}, k_{\text {bulk }} \sim 10^{3} ; k_{\text {film }} \sim 800\right)$ and $e t .^{6-9}$ However, the dielectric constant of the spontaneouspolarization ferroelectrics relies seriously on the temperature and the electric field applied to the ferroelectrics, causing uncertain response when writing data signal to the TFTs.

Recently, a new type of transistors, named electric-doublelayer (EDL) transistors, have been investigated as a candidate for low-voltage application by using polymer electrolytes or 
ionic liquids as gate dielectrics. ${ }^{\mathbf{1 0 - 1 2}}$ In such transistors, a high gate capacitance can be obtained by mobile ions that are able to move to form EDL, whose capacitance can be higher than $1 \mu \mathrm{F}$ $\mathrm{cm}^{-2}$ at low frequency. However, the speed of the ions is usually too slow for active-matrix displays, whose frame rate is $\sim 50$ 500 .

In 2000, Subramanian et al. found the "giant dielectric behaviour" $\left(k_{\text {bulk }}>10^{4}\right)$ in $\mathrm{CaCu}_{3} \mathrm{Ti}_{4} \mathrm{O}_{12}$ ceramics, ${ }^{13}$ which triggers a large number of studies on giant dielectric materials, e.g., $\mathrm{A}_{2 / 3} \mathrm{Cu}_{3} \mathrm{Ti}_{4} \mathrm{O}_{12}$ (A = Bi, La, Y), (Li, Ti) co-doped NiO, (In, Nb) codoped $\mathrm{TiO}_{2}\left(k_{\text {bulk }} \sim 10^{4} ; k_{\text {film }} \sim 4000\right)$, etc. ${ }^{14-18}$ However, attaining "giant dielectric" phase requires well-controlled deposition processes, specify substrates, and high annealing temperature $\left(>1000{ }^{\circ} \mathrm{C}\right)$, which is beyond the upper limit of glass substrates for TFTs.

In this paper, we demonstrate low-temperature $\left(400{ }^{\circ} \mathrm{C}\right)$ giant-dielectric-constant thin films $\left(\operatorname{In}_{0.0025} \mathrm{Nb}_{0.0025} \mathrm{Ti}_{0.995} \mathrm{O}_{2}\right)$ fabricated with simply radio frequency (RF) sputtering method for the gate dielectrics of the indium-zinc-oxide (IZO) TFTs on glass substrates. The $380 \mathrm{~nm}$-thick $\mathrm{In}_{0.0025^{-}}$ $\mathrm{Nb}_{0.0025} \mathrm{Ti}_{0.995} \mathrm{O}_{2}$ film exhibited a capacitance of as high as $7607 \mathrm{nF} \mathrm{cm}^{-2}$ with a permittivity of 3266 at $1 \mathrm{kHz}$. IZO-TFTs with $\mathrm{In}_{0.0025} \mathrm{Nb}_{0.0025} \mathrm{Ti}_{0.995} \mathrm{O}_{2}$ gate dielectrics exhibited high output current at low operation voltage and little hysteresis in the transfer curves between forward and reverse sweeps.
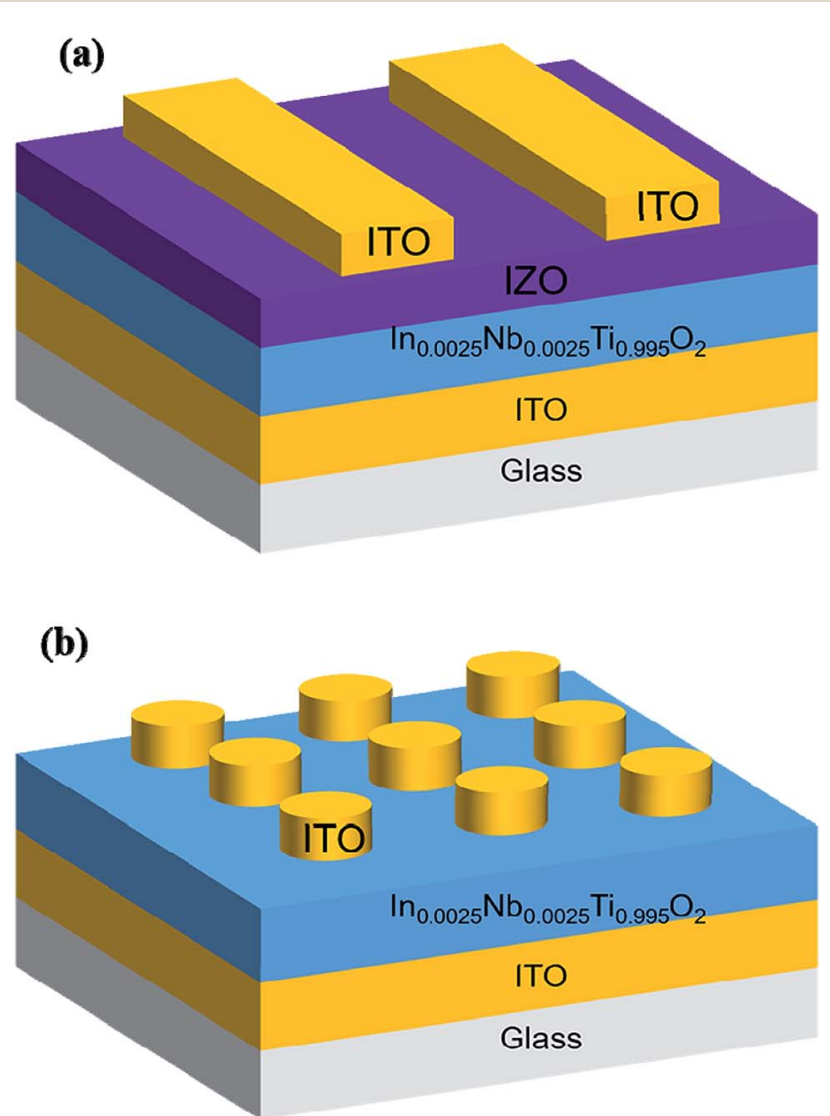

Fig. 1 Schematic structures of (a) the TFT with $\ln _{0.0025} \mathrm{Nb}_{0.0025}$ $\mathrm{Ti}_{0.995} \mathrm{O}_{2}$ gate insulator and (b) the capacitors with $1 \mathrm{TO} / \mathrm{In}_{0.0025^{-}}$ $\mathrm{Nb}_{0.0025} \mathrm{Ti}_{0.995} \mathrm{O}_{2} /$ ITO stacks.

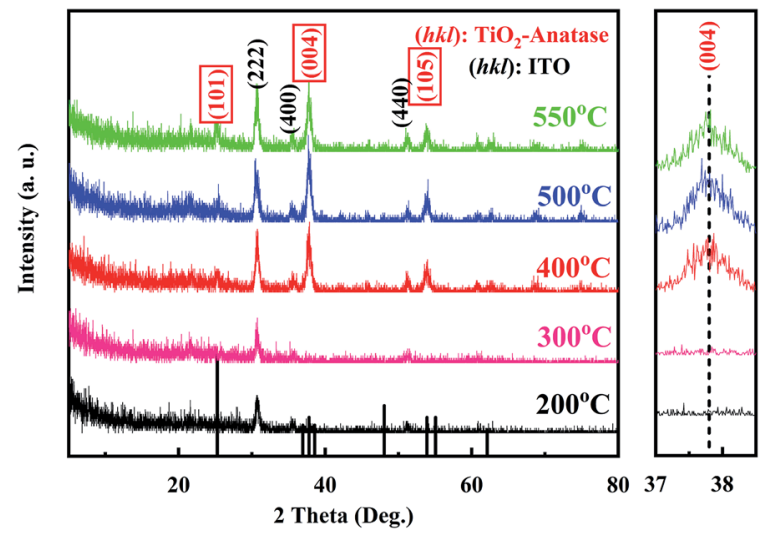

Fig. 2 XRD patterns of the $\ln _{0.0025} \mathrm{Nb}_{0.0025} \mathrm{Ti}_{0.995} \mathrm{O}_{2}$ films on ITO/glass substrates annealing at $200{ }^{\circ} \mathrm{C}, 300{ }^{\circ} \mathrm{C}, 400{ }^{\circ} \mathrm{C}, 500{ }^{\circ} \mathrm{C}$ and $550{ }^{\circ} \mathrm{C}$.

The micro structures and the mechanisms of the giant dielectric behaviour at low annealing temperature were discussed.

\section{Experimental}

\subsection{Device preparation}

The device structure of the IZO TFTs is shown in Fig. 1a. A layer of $150 \mathrm{~nm}$-thick indium-tin-oxide (ITO, In : $\mathrm{Sn}=9: 1$ ) gate electrode was fabricated on a glass substrate by direct current sputtering. Then, a layer of $380 \mathrm{~nm}$-thick $\mathrm{In}_{0.0025} \mathrm{Nb}_{0.0025^{-}}$ $\mathrm{Ti}_{0.995} \mathrm{O}_{2}$ film acting as the gate dielectric layer was deposited by $\mathrm{RF}$ magnetron sputtering with the $\operatorname{In}_{0.0025} \mathrm{Nb}_{0.0025} \mathrm{Ti}_{0.995} \mathrm{O}_{2}$ ceramics target under argon pressure of $0.5 \mathrm{~Pa}$, and annealed in air at $400{ }^{\circ} \mathrm{C}$ for 30 minutes. The IZO (In : $\mathrm{Zn}=2: 1$ ) semiconductor layer was deposited onto the gate dielectric layer by RF magnetron sputtering and annealed in air at $300{ }^{\circ} \mathrm{C}$ for 30 minutes. For the source and drain electrodes, a layer of $110 \mathrm{~nm}$-thick ITO was deposited through a shadow mask, defining a channel width/length of $800 / 200 \mu \mathrm{m}$. Finally, the

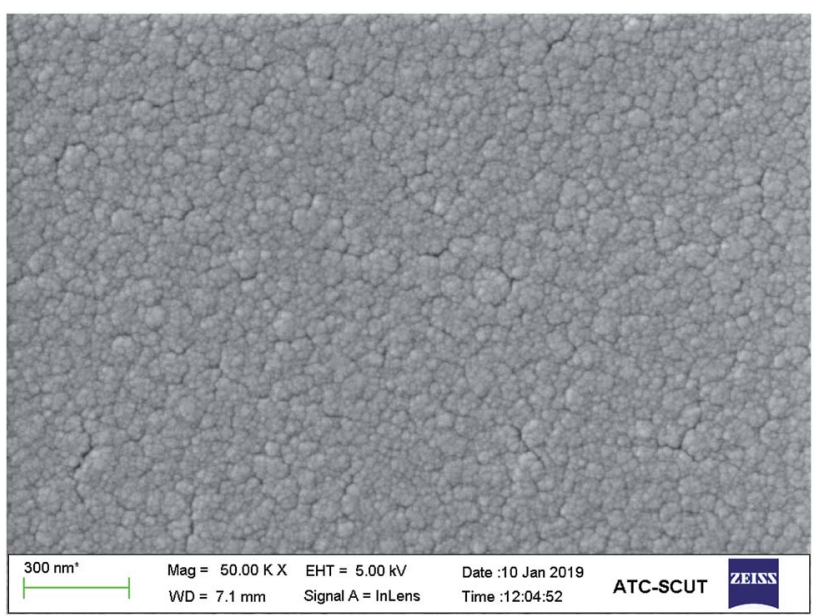

Fig. 3 SEM image of the $\ln _{0.0025} \mathrm{Nb}_{0.0025} \mathrm{Ti}_{0.995} \mathrm{O}_{2}$ film on ITO/glass substrates annealed at $400{ }^{\circ} \mathrm{C}$ for 30 minutes. 


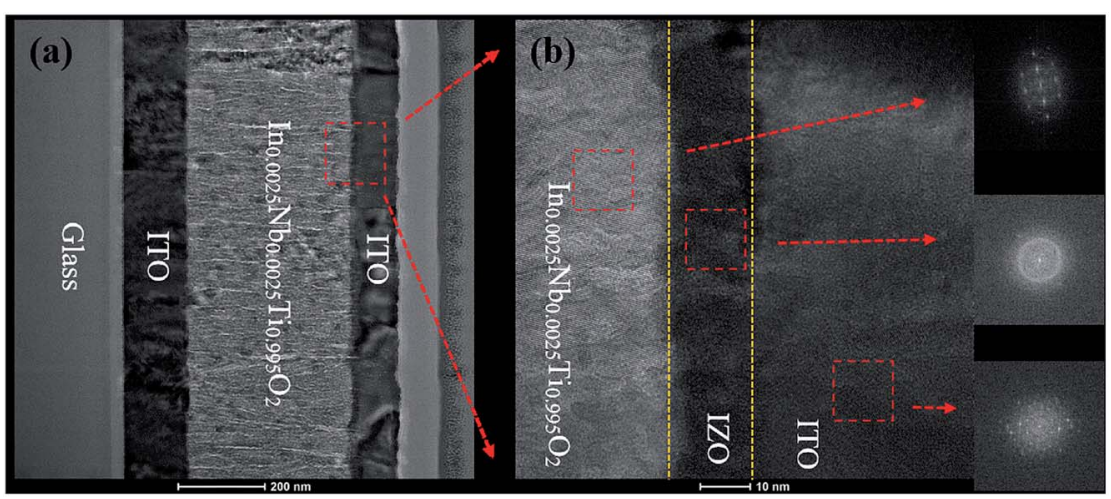

Fig. 4 (a) Cross-sectional STEM image of the Glass/ITO/In $\mathrm{n}_{0.0025} \mathrm{Nb}_{0.0025} \mathrm{Ti}_{0.995} \mathrm{O}_{2} / \mathrm{IZO} / \mathrm{ITO}$ sample annealed at $400{ }^{\circ} \mathrm{C}$ for $30 \mathrm{minutes}$; (b) the $\mathrm{HR}$-TEM image of the $\mathrm{In}_{0.0025} \mathrm{Nb}_{0.0025} \mathrm{Ti}_{0.995} \mathrm{O}_{2} / \mathrm{IZO} / \mathrm{ITO}$ region; the insets of (b) is the FFTs of the region of $\mathrm{In}_{0.0025} \mathrm{Nb}_{0.0025} \mathrm{Ti}_{0.995} \mathrm{O}$, IZO and ITO.

TFTs were annealed in air at $300{ }^{\circ} \mathrm{C}$ for 30 minutes. In addition, the metal-insulator-metal (MIM) capacitors were fabricated (see Fig. 1b).

\subsection{Characterization}

The $\mathrm{In}_{0.0025} \mathrm{Nb}_{0.0025} \mathrm{Ti}_{0.995} \mathrm{O}_{2}$ film structure and morphology were characterized by X-ray diffraction (XRD, Bruker D8 ADVANCE) and scanning electron microscopy (SEM, Zeiss Merlin), respectively. The chemical valence of each element of the $\operatorname{In}_{0.0025^{-}}$ $\mathrm{Nb}_{0.0025} \mathrm{Ti}_{0.995} \mathrm{O}_{2}$ film was characterized by X-ray photoelectron spectroscopy (XPS, Thermo Fisher Scientific Inc, ESCALAB
250Xi), and the spectra were calibrated with the $\mathrm{C}$ 1s peak (at $284.8 \mathrm{eV}$ ). Transmission electron microscopy (TEM, FEI Titan Themis 200) specimens of the TFT device was prepared by focused ion beam (FIB, HELIOS NANOLAB 450S). The electrical performance of the TFTs and the MIM capacitors were measured by semiconductor parameter analyzer (Keysight B1500A).

\section{Results and discussion}

Fig. 2 shows XRD patterns of $\operatorname{In}_{0.0025} \mathrm{Nb}_{0.0025} \mathrm{Ti}_{0.995} \mathrm{O}_{2}$ films on the ITO/glass substrates at different annealing

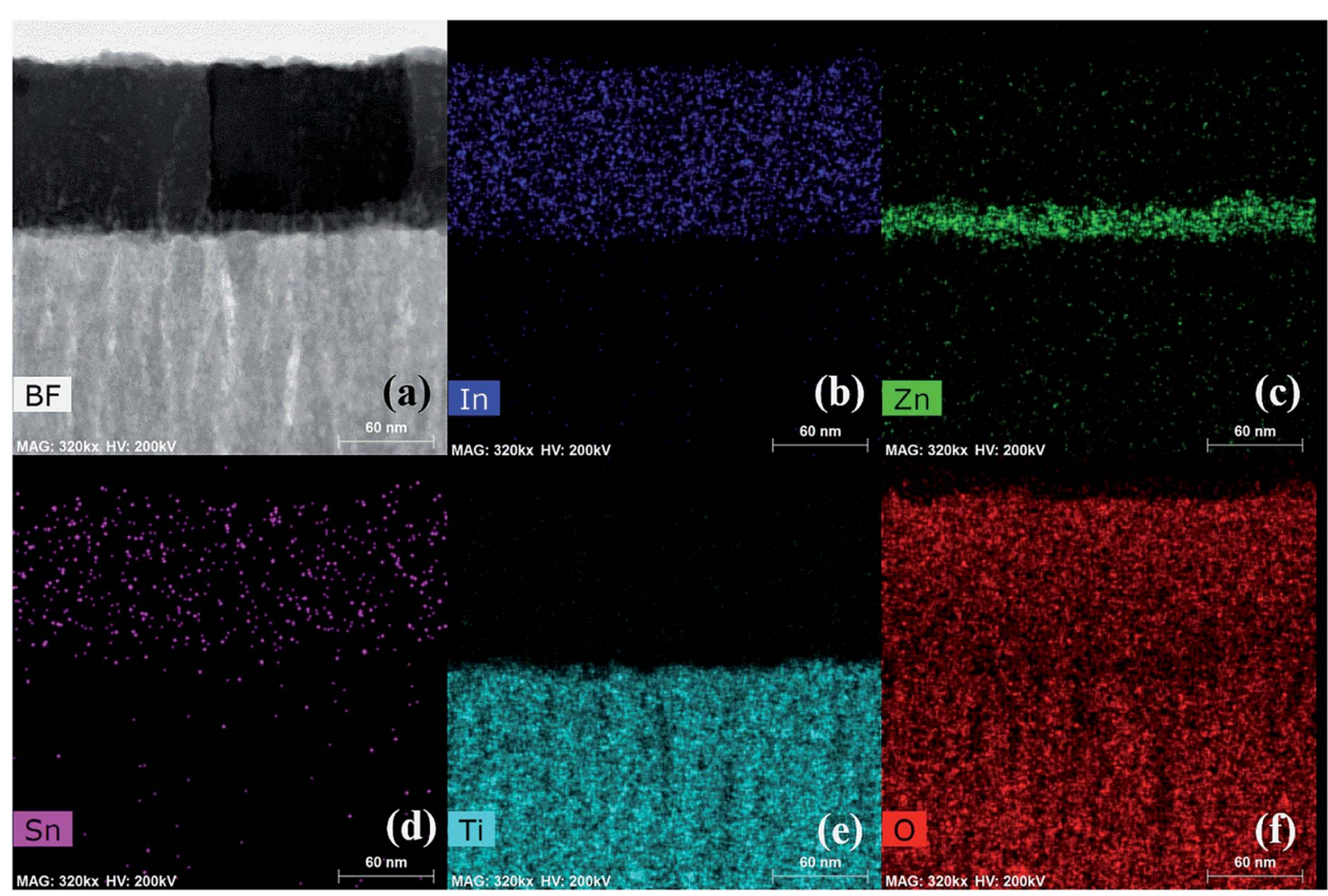

Fig. 5 (a) HAADF STEM images with elemental distribution detected by EDS for (b) In, (c) Zn, (d) Sn, (e) Ti, (f) O. 

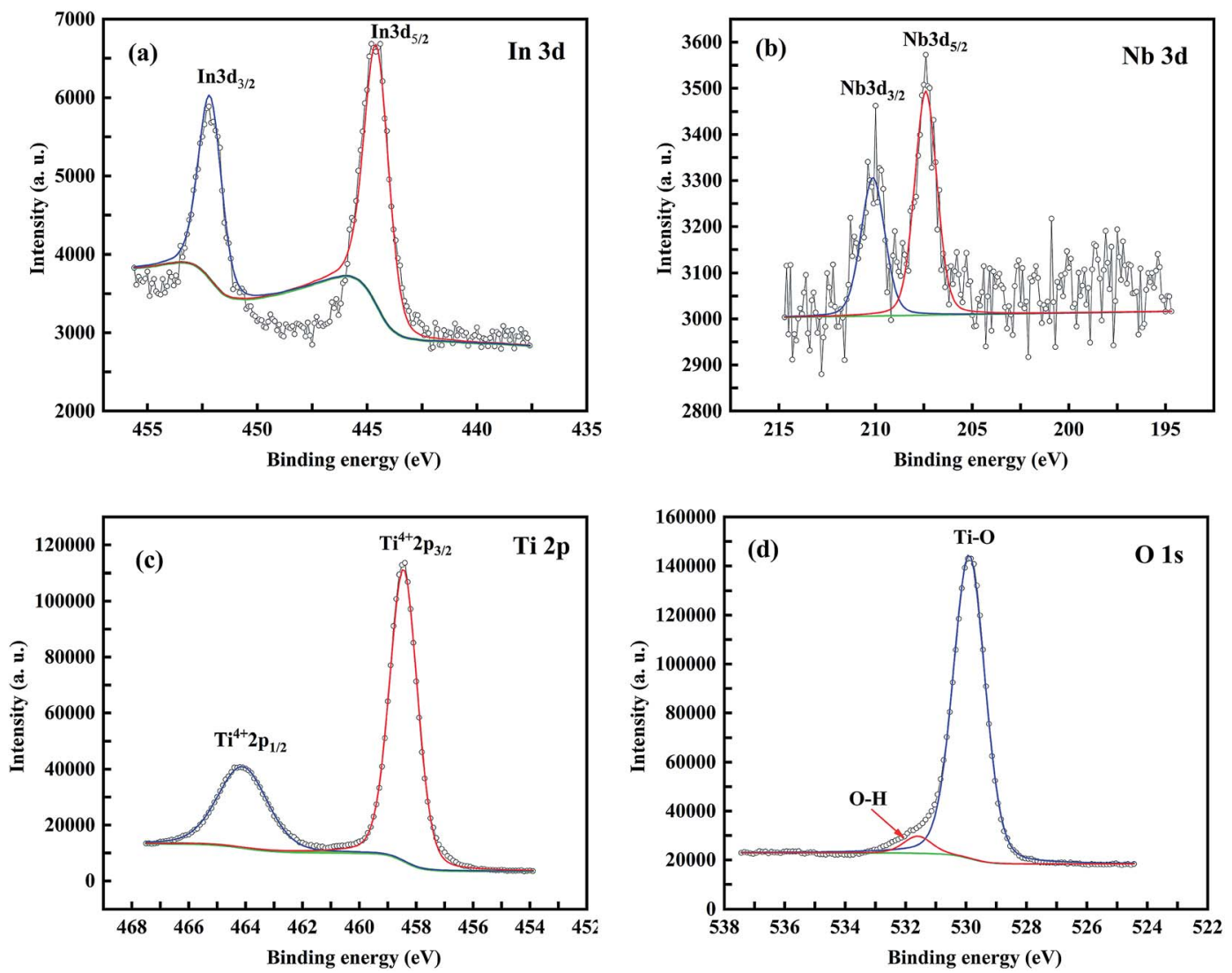

Fig. 6 XPS spectra of the $\ln _{0.0025} \mathrm{Nb}_{0.0025} \mathrm{Ti}_{0.995} \mathrm{O}_{2}$ films on ITO/glass substrates annealed at $400{ }^{\circ} \mathrm{C}$ for 30 minutes, including: (a) In $3 \mathrm{~d}$, (b) $\mathrm{Nb} 3 \mathrm{~d}$, (c) $\mathrm{Ti} 2 \mathrm{p}$, (d) $\bigcirc 1 \mathrm{~s}$

temperatures. The black strips at the bottom of Fig. 2 are the diffraction peaks for the standard anatase phase. For the films annealed at $200{ }^{\circ} \mathrm{C}$ and $300{ }^{\circ} \mathrm{C}$, the diffraction peaks of anatase phase could hardly be found, indicating that the $\mathrm{In}_{0.0025} \mathrm{Nb}_{0.0025} \mathrm{Ti}_{0.995} \mathrm{O}_{2}$ films were amorphous. When the annealing temperature increase to $400{ }^{\circ} \mathrm{C}$, the peaks of $\mathrm{TiO}_{2}$ anatase phase (including (101), (004), and (105)) ${ }^{19}$ were observed, indicating that the $\operatorname{In}_{0.0025} \mathrm{Nb}_{0.0025} \mathrm{Ti}_{0.995} \mathrm{O}_{2}$ films begin to crystallize. The strongest diffraction peak for the $\mathrm{In}_{0.0025} \mathrm{Nb}_{0.0025} \mathrm{Ti}_{0.995} \mathrm{O}_{2}$ films was peak (004), which was the third strongest diffraction peak for the standard anatase phase, indicating that the films crystallized with high $c$-axis orientation. The average crystalline sizes for the films annealing at $400{ }^{\circ} \mathrm{C}, 500{ }^{\circ} \mathrm{C}, 550{ }^{\circ} \mathrm{C}$, were calculated to be about $15.2 \mathrm{~nm}, 16.5 \mathrm{~nm}$ and $17.4 \mathrm{~nm}$, respectively, by using the Scherer equation. The diffraction peaks (including (222), (400), (440) $)^{20}$ of the $\operatorname{In}_{2} \mathrm{O}_{3}$ bixbyite phase were seem at the annealing temperature of $200{ }^{\circ} \mathrm{C}$, showing that the ITO films were easily to be crystallized even at low annealing temperature. The SEM image (Fig. 3) also showed that the $\mathrm{In}_{0.0025^{-}}$ $\mathrm{Nb}_{0.0025} \mathrm{Ti}_{0.995} \mathrm{O}_{2}$ film annealed at $400{ }^{\circ} \mathrm{C}$ were in polycrystalline state, which was consistent with the Fast Fourier Transform (FFT) patterns of the high-resolution transmission electron microscopy (HR-TEM) as discussed below.
Fig. 4a shows the scanning transmission electron microscopy (STEM) result of the cross-section of the glass/ITO/ $\mathrm{In}_{0.0025} \mathrm{Nb}_{0.0025} \mathrm{Ti}_{0.995} \mathrm{O}_{2} / \mathrm{IZO} / \mathrm{ITO}$ structure. Fig. $4 \mathrm{~b}$ shows the HR-TEM image and the FFT patterns of the $\operatorname{In}_{0.0025} \mathrm{Nb}_{0.0025^{-}}$ $\mathrm{Ti}_{0.995} \mathrm{O}_{2} / \mathrm{IZO} / \mathrm{ITO}$ region in Fig. $4 \mathrm{a}$. It was found that both of the $\operatorname{In}_{0.0025} \mathrm{Nb}_{0.0025} \mathrm{Ti}_{0.995} \mathrm{O}_{2}$ and ITO layers were crystallized, while the IZO film was in amorphous state. Fig. 5a-e show the high-angle annular dark-field (HAADF) STEM and elements distribution map obtained from energy-dispersion X-ray spectroscopy (EDS) of the $\operatorname{In}_{0.0025} \mathrm{Nb}_{0.0025} \mathrm{Ti}_{0.995} \mathrm{O}_{2} / \mathrm{IZO} / \mathrm{ITO}$ region. It could be seen that the elements were distributed uniformly in each film without segregated clusters. Because the signals of the elements (In and $\mathrm{Nb}$ ) are too weak to be detected by EDS, they were characterized by XPS, as shown in Fig. $6 \mathrm{a}$ and $\mathrm{b}$. The binding energies of In $3 \mathrm{~d}$ electrons are $452.4 \mathrm{eV}$ and $444.6 \mathrm{eV}$ for $3 \mathrm{~d}_{3 / 2}$ and $3 \mathrm{~d}_{5 / 2}$, respectively, ${ }^{21}$ while the binding energies of $\mathrm{Nb} 3 \mathrm{~d}$ electrons are $210.1 \mathrm{eV}$ and $207.3 \mathrm{eV}$ for $3 \mathrm{~d}_{3 / 2}$ and $3 \mathrm{~d}_{5 / 2}$, respectively. And the spin orbit splitting between the $\mathrm{Nb} 3 \mathrm{~d}_{3 / 2}$ and $3 \mathrm{~d}_{5 / 2}$ was $2.8 \mathrm{eV}$, showing that the valence of $\mathrm{Nb}$ in the $\mathrm{In}_{0.0025} \mathrm{Nb}_{0.0025} \mathrm{Ti}_{0.995} \mathrm{O}_{2}$ was $+5 .^{22}$ Fig. $6 \mathrm{c}$ shows the binding energy spectra for the Ti $2 \mathrm{p}$ electrons (464.10 eV and $458.45 \mathrm{eV}$ are for $2 \mathrm{p}_{1 / 2}$ and $2 \mathrm{p}_{3 / 2}$, respectively). ${ }^{22,23}$ The doublet separation of Ti $2 \mathrm{p}_{1 / 2}$ and $2 \mathrm{p}_{3 / 2}$ peaks was $5.65 \mathrm{eV}$, which shows that the $\mathrm{Ti}^{4+}$ was the main state. Fig. $6 \mathrm{~d}$ shows the XPS spectra for O 1s. The peak at $529.84 \mathrm{eV}$ 
was related to the Ti-O bonds while the peak at $531.4 \mathrm{eV}$ was related to the oxygen vacancies or hydroxyl $(\mathrm{OH})$ groups. ${ }^{24}$ The results indicate that $\left[\mathrm{Ti}^{4+} \cdot \mathrm{e}-\mathrm{V}_{\mathrm{o}}^{*}-\mathrm{Ti}^{4+} \cdot \mathrm{e}\right]$-related defects can be formed. ${ }^{17}$ However, no peaks related to $\mathrm{Ti}^{3+}$ was observed. It means that the giant dielectric behaviour of $\mathrm{In}_{0.0025} \mathrm{Nb}_{0.0025} \mathrm{Ti}_{0.995} \mathrm{O}_{2}$ was not due to the electron hoping between $\mathrm{Ti}^{4+}$ and $\mathrm{Ti}^{3+}$, which will be discussed later.

Fig. 7a shows the frequency dependences of capacitance and permittivity of the ITO/In $\operatorname{In}_{0.0025} \mathrm{Nb}_{0.0025} \mathrm{Ti}_{0.995} \mathrm{O}_{2} / \mathrm{ITO}$ capacitors. The areal capacitance $\left(C_{\mathrm{i}}\right)$ was as high as $7607 \mathrm{nF}$ $\mathrm{cm}^{-2}$ with a corresponding permittivity of 3266 at $1 \mathrm{kHz}$ (the

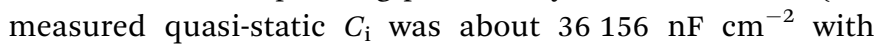
a quasi-static permittivity of 15 525), as shown in Fig. 7b. But the permittivity reduced rapidly when the frequency increased from $1 \mathrm{kHz}$ to $10 \mathrm{kHz}$, which is inconsistent with the singlecrystal $\mathrm{TiO}_{2}$-based giant dielectrics. ${ }^{25}$ The strongly-frequencydependent permittivity was ascribed to the extrinsic polarization mechanism, in which the electrons accumulated near the grain boundaries (see Fig. 3) and causing space-charge polarization. Although the permittivity reduced rapidly at higher frequency, the highest frequency required for the active-matrix displays is only $500 \mathrm{~Hz}$ (for the high-frame-rate 3D displays). Fig. 8 shows the input and output voltage of a resistor-loaded inverter with an $\operatorname{In}_{0.0025} \mathrm{Nb}_{0.0025} \mathrm{Ti}_{0.995} \mathrm{O}_{2} / \mathrm{IZO}$ TFT and
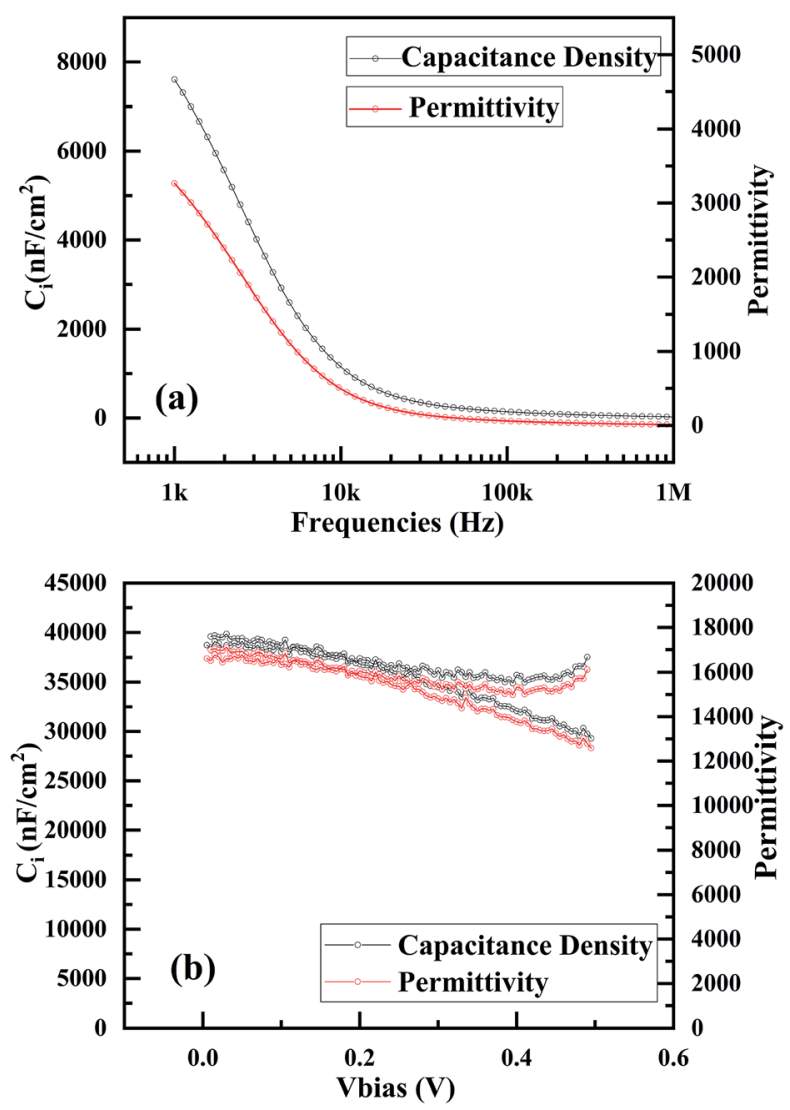

Fig. 7 (a) The frequency dependences of capacitance density (black curve) and permittivity (red curve), (b) the quasi-static $C_{\mathrm{i}}-V$ curve of the capacitor with the $1 \mathrm{TO} / \mathrm{In}_{0.0025} \mathrm{Nb}_{0.0025} \mathrm{Ti}_{0.995} \mathrm{O}_{2} / \mathrm{ITO}$ structure annealed at $400{ }^{\circ} \mathrm{C}$ for 30 minutes. a resistor $(100 \mathrm{k} \Omega)$ at $500 \mathrm{~Hz}$. It shows that the output voltage of the inverter responded well to a $500 \mathrm{~Hz}$ square-wave input voltage signal, which are fast enough for applications to activematrix displays. The comparison for different kinds of gate dielectrics for the TFTs is shown in Table 1.

Fig. 9 shows the leakage current density versus voltage curve of the ITO/In $\mathrm{In}_{0.0025} \mathrm{Nb}_{0.0025} \mathrm{Ti}_{0.995} \mathrm{O}_{2} / \mathrm{ITO}$ capacitor. The breakdown field was $64.2 \mathrm{kV} \mathrm{cm}{ }^{-1}$. The relatively high leakage current might be attributed to the electron conduction in the crystalline grains. Fig. 10a and b show the output and the transfer characteristics $\left(I_{\mathrm{D}}-V_{\mathrm{D}}\right.$ curve and $I_{\mathrm{D}}-V_{\mathrm{G}}$ curve $)$ of the IZO-TFT with $\operatorname{In}_{0.0025} \mathrm{Nb}_{0.0025} \mathrm{Ti}_{0.995} \mathrm{O}_{2}$ gate dielectric, respectively. The operation voltage is only $1 \mathrm{~V}$. No "current crowding" effects is observed at low drain voltage $\left(V_{\mathrm{D}}\right)$ in the output curves, implying ohmic contacts between ITO S/D electrodes and IZO active layer. It is worth noting that there was not quadratic increase of saturation $I_{\mathrm{D}}$ with increasing $V_{\mathrm{G}}$, which is because of space-charge polarization, in which some of the accumulated space charges will leak out at higher gate voltage (causing lowering of the permittivity). There was little hysteresis for the transfer curves between the forward and reverse sweeps (the measuring condition was presented in the ESI, see Fig. S2 $\dagger$ ), which was different from the TFTs with ferroelectric gate dielectrics. The threshold voltage $\left(V_{\text {th }}\right)$ was $0.35 \mathrm{~V}$. The mobility $(\mu)$ was calculated to be $1.88 \mathrm{~cm}^{2} \mathrm{~V}^{-1} \mathrm{~s}^{-1}$ using the quasi-static capacitance. The mobility and $V_{\text {th }}$ distributions of the IZO-TFT with the $\mathrm{In}_{0.0025} \mathrm{Nb}_{0.0025} \mathrm{Ti}_{0.995} \mathrm{O}_{2}$ gate dielectric are shown in Fig. S1. $\dagger$ The average mobility of the devices was $1.94 \mathrm{~cm}^{2} \mathrm{~V}^{-1} \mathrm{~s}^{-1}$, and the maximum mobility was $2.21 \mathrm{~cm}^{2} \mathrm{~V}^{-1} \mathrm{~s}^{-1}$. The average $V_{\text {th }}$ was $0.35 \mathrm{~V}$. It is worth noting that the stability under gate bias stress was not good (the shift of $V_{\text {th }}$ was $-0.31 \mathrm{~V}$ under
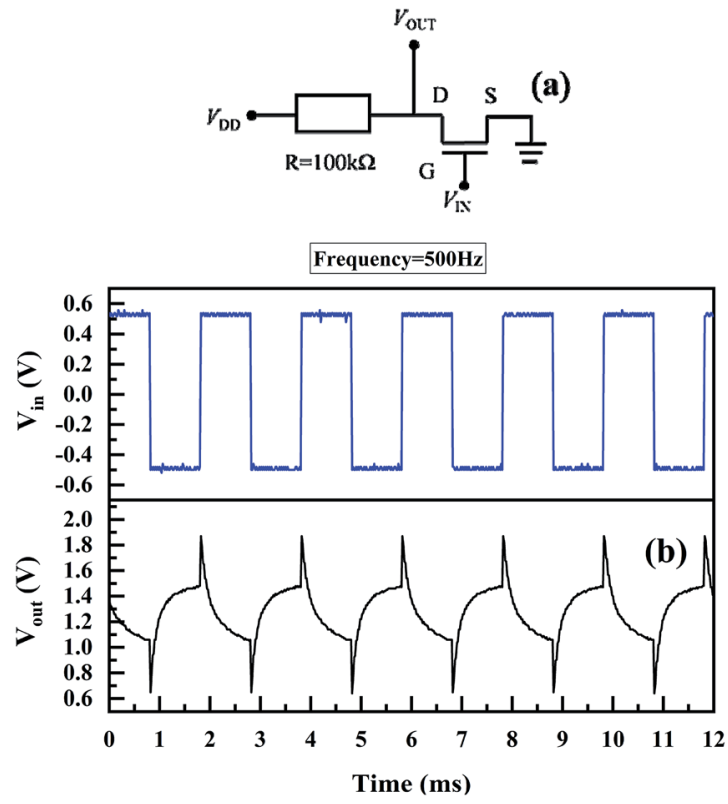

Fig. 8 (a) The circuit of the inverter; (b) the input and output voltage of a resistor-loaded inverter with an $\ln _{0.0025} \mathrm{Nb}_{0.0025} \mathrm{Ti}_{0.995} \mathrm{O}_{2} / \mathrm{IZO}$ TFT and a resistor $(100 \mathrm{k} \Omega)$ at $500 \mathrm{~Hz}\left(V_{\mathrm{DD}}=1.8 \mathrm{~V}\right)$. 
Table 1 Comparison of different kinds of high dielectric constant gate insulator for TFTs

\begin{tabular}{|c|c|c|c|c|c|c|c|c|c|}
\hline Dielectric materials & Dielectric types & $C_{\mathrm{i}}\left(\mu \mathrm{F} \mathrm{cm}{ }^{-2}\right)$ & $\begin{array}{l}\text { Gate insulator } \\
\text { thickness (nm) }\end{array}$ & $k$ & $\begin{array}{l}\text { SS } \\
\left(\mathrm{mV} \mathrm{dec}{ }^{-1}\right)\end{array}$ & $\begin{array}{l}\text { Channel } \\
\text { layer }\end{array}$ & $\begin{array}{l}\text { Mobility } \\
\left(\mathrm{cm}^{2} \mathrm{~V}^{-1} \mathrm{~s}^{-1}\right)\end{array}$ & Ref. & Year \\
\hline $\mathrm{HfO}_{2}$ & High- $k$ materials & $0.151(100 \mathrm{~Hz})$ & 104 & 18.5 & $\sim 180$ & $\mathrm{ZnO}$ & 40 & 1 & 2015 \\
\hline 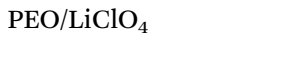 & $\begin{array}{l}\text { Polymer } \\
\text { electrolyte }\end{array}$ & 100 & $\sim 3000$ & $\sim 3.4 \times 10^{5}$ & - & P3HT & 0.7 & 9 & 2005 \\
\hline DEME-TFSI & Ionic liquid & $0.12(0.01 \mathrm{~Hz})$ & $\sim 10000$ & $\sim 1350$ & 100 & $\mathrm{ZnO}$ & - & 10 & 2009 \\
\hline Mesoporous $\mathrm{SiO}_{2}$ & $\begin{array}{l}\text { Proton } \\
\text { conduction }\end{array}$ & $1.7(40 \mathrm{~Hz})$ & $\sim 4000$ & $\sim 7680$ & 110 & $\mathrm{InGaZnO}_{4}$ & 28.5 & 11 & 2009 \\
\hline $\mathrm{Ba}_{0.7} \mathrm{Sr}_{0.3} \mathrm{TiO}_{3}$ & Ferroelectrics & $0.261(40 \mathrm{~Hz})$ & 670 & $\sim 200$ & 260 & Pentacene & 1.24 & 4 & 2012 \\
\hline $\mathrm{In}_{0.0025} \mathrm{Nb}_{0.0025} \mathrm{Ti}_{0.995} \mathrm{O}_{2}$ & Giant-dielectrics & $\begin{array}{l}7.6(1 \mathrm{kHz}) \\
36.1 \text { (quasi-static) }\end{array}$ & 380 & $\begin{array}{l}3255 \\
15525\end{array}$ & 68 & $\mathrm{IZO}$ & 1.88 & $\begin{array}{l}\text { This } \\
\text { work }\end{array}$ & 2019 \\
\hline
\end{tabular}

negative bias stress for $1 \mathrm{~h}$, see Fig. $\mathrm{S} 3 \uparrow$ ), which may be attributed to the defects at the interface between $\mathrm{In}_{0.0025^{-}}$ $\mathrm{Nb}_{0.0025} \mathrm{Ti}_{0.995} \mathrm{O}_{2}$ and IZO.

Fig. 10c shows the SS as a function of $V_{\mathrm{G}}$ in the subthreshold regime. Theoretically, SS is expressed as,

$$
\mathrm{SS}=\frac{\partial V_{\mathrm{G}}}{\partial\left(\log _{10} I_{\mathrm{D}}\right)}=\frac{\partial V_{\mathrm{G}}}{\partial \psi_{\mathrm{s}}} \frac{\partial \psi_{\mathrm{s}}}{\partial\left(\log _{10} I_{\mathrm{D}}\right)}
$$

where $\Psi_{\mathrm{s}}$ is the surface potential of the semiconductor channel at the gate dielectric/semiconductor interface. $\partial V_{\mathrm{G}} / \partial \Psi_{\mathrm{s}}$ given by

$$
\frac{\partial V_{\mathrm{G}}}{\partial \psi_{\mathrm{s}}}=1+\frac{C_{\mathrm{s}}}{C_{\mathrm{ins}}}
$$

where $C_{\mathrm{s}}$ is the capacitance of the semiconductor and $C_{\text {ins }}$ is the capacitance of the gate dielectric, must exceed one (except for the negative capacitance). Because the carriers are confined into an ultrathin layer in close proximity to the gate dielectric/

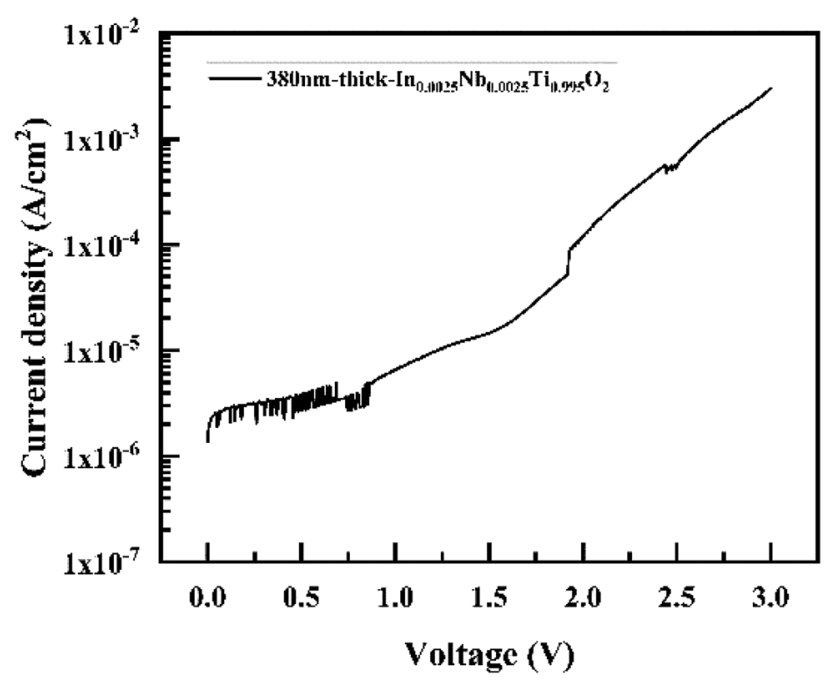

Fig. 9 The leakage current density versus voltage curve of the ITO/ $\ln _{0.0025} \mathrm{Nb}_{0.0025} \mathrm{Ti}_{0.995} \mathrm{O}_{2} /$ ITO capacitor annealed at $400{ }^{\circ} \mathrm{C}$ for 30 minutes. semiconductor interface, it is reasonable to assume that the carrier distribution within this ultrathin layer is uniform. Thus $I_{\mathrm{D}}$ can be expressed as

$$
I_{\mathrm{D}}=n e v S=n_{\mathrm{D}} \exp \left(\frac{e \psi_{\mathrm{s}}}{k T}\right) e v S
$$

where $n$ is the carrier (electron) density at the interface, $e$ is the electron charge, $v$ is the electron velocity in the semiconductor, $S$ is the lateral area of the channel, $n_{\mathrm{D}}$ is the donor density, $k$ is Boltzmann constant, and $T$ is the absolute temperature. Thus,

$$
\begin{aligned}
& \partial\left(\log _{10} I_{\mathrm{D}}\right)=\partial\left\{\log _{10}\left[n_{\mathrm{D}} \exp \left(\frac{e \psi_{\mathrm{s}}}{k T}\right) e v S\right]\right\} \\
& =\partial\left\{\frac{1}{\ln _{10}} \ln \left[n_{\mathrm{D}} \exp \left(\frac{e \psi_{\mathrm{s}}}{k T}\right) e v S\right]\right\} \\
& =\frac{1}{\ln _{10}} \partial\left[\frac{e \psi_{\mathrm{s}}}{k T}+\ln \left(n_{\mathrm{D}} e v S\right)\right] \\
& =\frac{1}{\ln _{10}} \partial\left(\frac{e \psi_{\mathrm{s}}}{k T}\right) \\
& \frac{\partial \psi_{\mathrm{s}}}{\partial\left(\log _{10} I_{\mathrm{D}}\right)}=\frac{\ln _{10} \partial \psi_{\mathrm{s}}}{\partial\left(\frac{e \psi_{\mathrm{s}}}{k T}\right)}=\frac{\ln _{10} k T}{e} \approx 0.06
\end{aligned}
$$

It can be deduced from eqn (2), (3) and (6) that SS should be greater than $0.06 \mathrm{~V} \mathrm{dec}{ }^{-1} .{ }^{26}$ For the IZO TFTs with $\mathrm{In}_{0.0025^{-}}$ $\mathrm{Nb}_{0.0025} \mathrm{Ti}_{0.995} \mathrm{O}_{2}$ gate dielectrics, the gate leakage current of the forward sweep and much higher than that of the reverse sweep (see Fig. 10b), so the SS of the forward-sweep transfer curve was affected by the gate leakage current. For the reverse sweep of the transfer curve, the off current $\left(I_{\text {off }}\right)$ was much higher than the gate leakage current, so the SS of the reverse-sweep transfer curve was more accurate. It can be seen from Fig. 10c that the SS of the reverse-sweep transfer curve was about $0.068 \mathrm{~V} \mathrm{dec}^{-1}$, very close to the lowest limit of the SS of the field-effect transistors $\left(0.06 \mathrm{~V} \mathrm{dec}^{-1}\right)$. And the SS is the same as the IGZO-TFTs with ultrathin $\mathrm{Al}_{x} \mathrm{O}_{y}$ gate dielectrics $(\sim 3 \mathrm{~nm}) .^{27}$ These results prove 

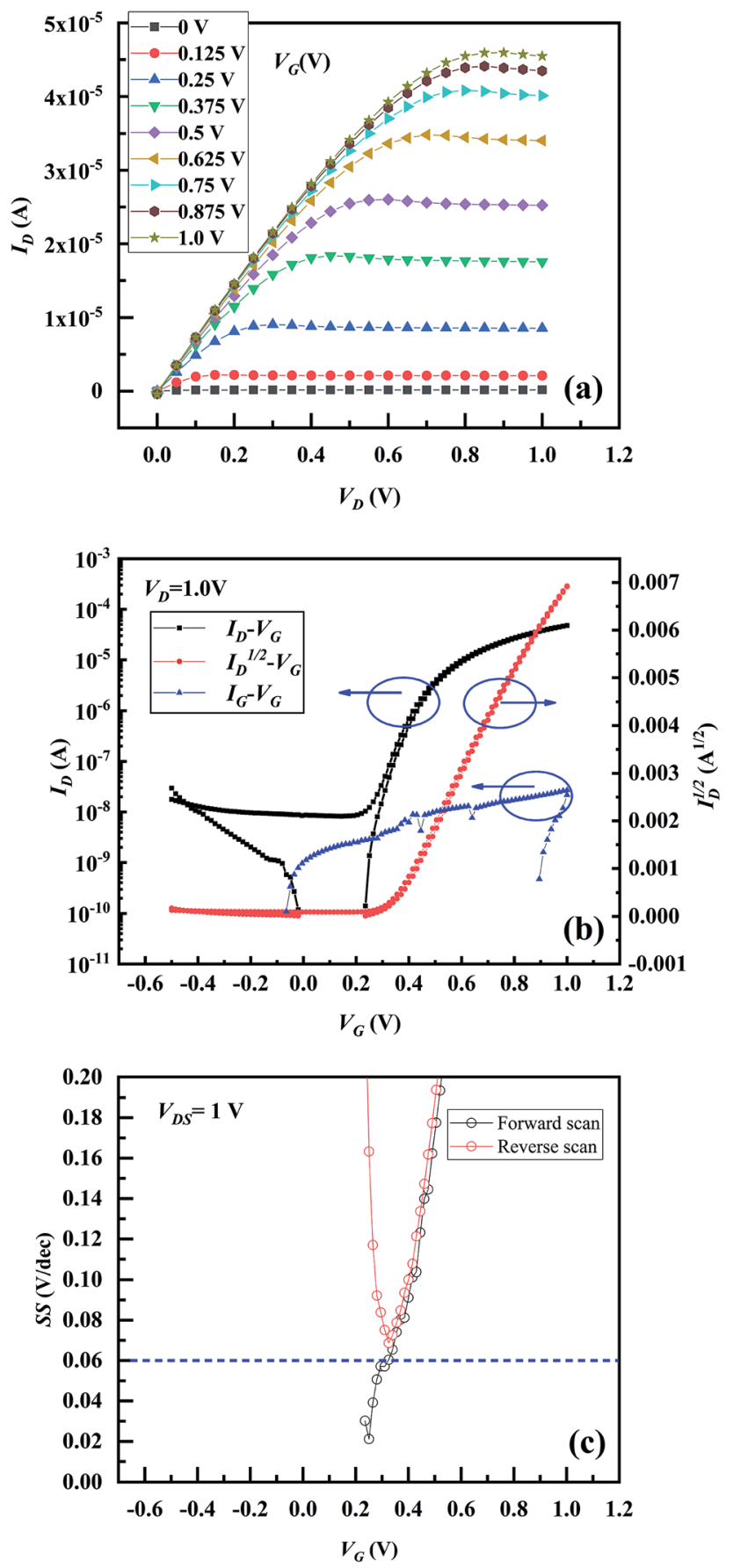

Fig. 10 (a) The output curve, (b) the transfer curve and (c) the SS- $V_{G}$ curve of the IZO-TFT with the $\ln _{0.0025} \mathrm{Nb}_{0.0025} \mathrm{Ti}_{0.995} \mathrm{O}_{2}$ insulator.

that the lowest limit of the SS $\left(0.06 \mathrm{~V} \mathrm{dec}^{-1}\right)$ of the filed-effect transistors cannot be broken no matter how high the gate dielectric capacitance is (except for ferroelectric negative capacitors).

\section{Conclusion}

In conclusion, low-temperature $\left(400{ }^{\circ} \mathrm{C}\right)$ giant-dielectricconstant thin films $\left(\operatorname{In}_{0.0025} \mathrm{Nb}_{0.0025} \mathrm{Ti}_{0.995} \mathrm{O}_{2}\right)$ fabricated with simply radio frequency $(\mathrm{RF})$ sputtering on glass substrates are employed as the gate dielectrics for thin-film transistors (TFTs) for the first time. The $380 \mathrm{~nm}$-thick $\operatorname{In}_{0.0025} \mathrm{Nb}_{0.0025} \mathrm{Ti}_{0.995} \mathrm{O}_{2}$ film was in polycrystalline state with a quasi-static capacitance of as high as $36156 \mathrm{nF} \mathrm{cm}$ cm $^{-2}$ with a quasi-static permittivity of 15525 , and the capacitance was as high as $7607 \mathrm{nF} \mathrm{cm}^{-2}$ with a corresponding permittivity of 3266 at $1 \mathrm{kHz}$. Indium zinc oxide (IZO) TFTs with $\mathrm{In}_{0.0025} \mathrm{Nb}_{0.0025} \mathrm{Ti}_{0.995} \mathrm{O}_{2}$ gate dielectrics exhibited high output current (the mobility was $1.88 \mathrm{~cm}^{2} \mathrm{~V}^{-1}$ $\mathrm{s}^{-1}$, and the $V_{\text {th }}$ was $0.35 \mathrm{~V}$.) at low operation voltage (less than 1 $\mathrm{v})$ and little hysteresis in the transfer curves between forward and reverse sweeps. The subthreshold swing (SS) of the IZO TFTs is $0.068 \mathrm{~V} \mathrm{dec}^{-1}$, very close to the lowest limit of the SS of the field-effect transistors $\left(0.06 \mathrm{~V} \mathrm{dec}^{-1}\right)$. The results also proves that the lowest limit of the SS $\left(0.06 \mathrm{~V} \mathrm{dec}^{-1}\right)$ of the field-effect transistors cannot be broken no matter how high the gate dielectric capacitance is (except for negative capacitors). The TFTs demonstrate the potential for the application of low-power circuits and flat-panel displays.

\section{Conflicts of interest}

There are no conflicts to declare.

\section{Acknowledgements}

This work was supported by the National Key R\&D Program (Grant No. 2016YFB0401105), the National Natural Science Foundation of China (Grant No. 51673068), the Guangdong Province Science and Technology Plan (Grant No. 2017A050503002 and 2016B090906002), the Guangdong Natural Science Foundation (Grant No. 2017A030306007), and the Fundamental Research Funds for the Central Universities.

\section{Notes and references}

1 L. Zhou, M. Xu, X. Xia, J. Zou, L. Zhang, D. Luo, W. Wu, L. Wang and J. Peng, J. Disp. Technol., 2016, 12, 1064.

2 M. Esro, G. Vourlias, C. Somerton, W. I. Milne and G. Adamopoulos, Adv. Funct. Mater., 2015, 25, 134.

3 J. M. Lee, I. T. Cho, J. H. Lee, W. S. Cheong, C. S. Hwang and H. I. Kwon, Appl. Phys. Lett., 2009, 94, 222112.

4 J. H. Li, Z. H. Sun and F. Yan, Adv. Mater., 2012, 24, 88.

5 Z. R. Wang, J. Z. Xin, X. C. Ren, X. L. Wang, C. W. Leung, S. Q. Shi, A. Ruotolo and P. K. L. Chan, Org. Electron., 2012, 13, 1223.

6 Z. Zhao, V. Buscaglia, M. Viviani, M. T. Buscaglia, L. Mitoseriu, A. Testino, M. Nygren, M. Johnsson and P. Nanni, Phys. Rev. B Condens. Matter, 2004, 70, 024107.

7 B. H. Hoerman, G. M. Ford, L. D. Kaufmann and B. W. Wessels, Appl. Phys. Lett., 1998, 73, 2248.

8 N. Uchida and T. Ikeda, Jpn. J. Appl. Phys., 1965, 4, 867.

9 S. Krupanidhi, N. Maffei, M. Sayer and K. El-Assal, J. Appl. Phys., 1983, 54, 6601.

10 M. J. Panzer and C. D. Frisbie, Adv. Funct. Mater., 2006, 16, 1051.

11 H. T. Yuan, H. Shimotani, A. Tsukazaki, A. Ohtomo, M. Kawasaki and Y. Iwasa, Adv. Funct. Mater., 2009, 19, 1046. 
12 J. Jiang, Q. Wan, J. Sun and A. X. Lu, Appl. Phys. Lett., 2009, 95, 152114.

13 A. P. Ramirez, M. A. Subramanian, M. Gardel, G. Blumberg, D. Li, T. Vogt and S. M. Shapiro, Solid State Commun., 2000, 115, 217.

14 M. A. Subramanian, D. Li, N. Duan, B. A. Reisner and A. W. Sleight, J. Solid State Chem., 2000, 151, 323.

15 B. S. Prakash and K. B. R. Varma, Phys. B, 2006, 382, 312.

16 J. B. Wu, C. W. Nan, Y. H. Lin and Y. Deng, Phys. Rev. Lett., 2002, 89, 217601.

17 W. B. Hu, Y. Liu, R. L. Withers, T. J. Frankcombe, L. Noren, A. Snashall, M. Kitchin, P. Smith, B. Gong, H. Chen, J. Schiemer, F. Brink and J. Wong-Leung, Nat. Mater., 2013, $12,821$.

18 Z. G. Gai, Z. X. Cheng, X. L. Wang, L. L. Zhao, N. Yin, R. Abah, M. Zhao, F. Hong, Z. Y. Yu and S. X. Dou, J. Mater. Chem. C, 2014, 2, 6790.

19 Y. Masuda and K. Kato, Chem. Mater., 2008, 20, 1057.
20 W. Song, L. F. Lan, P. Xiao, Z. G. Lin, S. Sun, Y. Z. Li, E. L. Song, P. X. Gao, P. Zhang, H. Xu, D. X. Luo, M. Xu and J. B. Peng, J. Phys. D: Appl. Phys., 2016, 49, 24 LT01.

21 E. J. Wang, W. S. Yang and Y. A. Cao, J. Phys. Chem. C, 2009, 113, 20912.

22 D. Morris, Y. Dou, J. Rebane, C. E. J. Mitchell, R. G. Egdell, D. S. L. Law, A. Vittadini and M. Casarin, Phys. Rev. B Condens. Matter, 2000, 61, 13445.

23 I. Ganesh, A. K. Gupta, P. P. Kumar, P. S. C. Sekhar, K. Radha, G. Padmanabham and G. Sundararajan, Mater. Chem. Phys., 2012, 135, 220.

24 E. Ramos-Moore, P. Ferrari, D. E. Diaz-Droguett, D. Lederman and J. T. Evans, J. Appl. Phys., 2012, 111, 014108.

25 Y. L. Song, X. J. Wang, Y. Sui, Z. Y. Liu, Y. Zhang, H. S. Zhan, B. Q. Song, Z. G. Liu, Z. Lv, L. Tao and J. K. Tang, Sci. Rep., 2016, 6, 21478.

26 S. Salahuddin and S. Dattat, Nano Lett., 2008, 8, 405.

27 W. Cai, S. Park, J. Zhang, J. Wilson, Y. Li, Q. Xin, L. Majewski and A. Song, IEEE Electron Device Lett., 2018, 39, 375. 